\title{
Severity of Mitral Stenosis and Left Ventricular Mechanics: A Speckle Tracking Study
}

\author{
Emine Bilen $^{a} \quad$ Mustafa Kurt $^{\mathrm{b}} \quad$ Ibrahim Halil Tanboga $^{\mathrm{b}} \quad$ Ahmet Kaya $^{\mathrm{b}}$ \\ Turgay Isik $^{\mathrm{b}}$ Mehmet Ekinci ${ }^{\mathrm{b}} \quad$ Mehmet Mustafa Can ${ }^{\mathrm{d}}$ Mehmet Fatih Karakas ${ }^{\mathrm{a}}$ \\ Vecih Oduncu $^{d}$ Ednan Bayram $^{b}$ Enbiya Aksakal ${ }^{c}$ Serdar Sevimlic \\ ${ }^{a}$ Ankara Ataturk Education and Research Hospital, Ankara, ${ }^{b}$ Erzurum Education and Research Hospital and \\ 'School of Medicine, Ataturk University, Erzurum, and d Kosuyolu Heart Hospital, Istanbul, Turkey
}

\section{Key Words}

Echocardiography $\cdot$ Left ventricular function $\cdot$ Mitral stenosis

\begin{abstract}
Background: It has been shown that mitral stenosis (MS) impairs left ventricular (LV) systolic function; however, this issue has not been studied comprehensively. We aimed to evaluate the role of $2 \mathrm{D}$ strain in the assessment of subclinical LV systolic dysfunction in patients with MS. Methods: Seventytwo patients with isolated MS (mild, moderate and severe) and 31 healthy control subjects constituted the study population. 2D echocardiography images were obtained from LV apical 4-chamber (4C), long axis (LAX), and 2-chamber (2C) views. Peak longitudinal strain and strain rate $(\mathrm{Sr})$ were obtained from $4 C$, LAX, and 2 C views. Global strain and Sr were calculated by averaging the three apical views. Results: There were no significant differences in LV ejection fraction and LV systolic or diastolic dimensions between the groups. Patients with MS had significantly lower LV longitudinal strain and $\mathrm{Sr}$ measurements than the control group. In addition, there were no significant differences in MS subgroups with respect to LV strain and Sr measurements. Conclusion: We demonstrated that patients with MS had lower LV func-
\end{abstract}

tions using $2 \mathrm{D}$ strain imaging, and this is independent of the hemodynamic severity of MS. In the detection of subclinical LV dysfunction in patients with MS, 2D strain imaging appears to be useful.

Copyright $\odot 2011$ S. Karger AG, Basel

\section{Introduction}

Although there is a downward trend in the prevalence of mitral stenosis (MS) in developed countries, it stands out as a huge public health problem in developing countries [1-3]. It is accepted that isolated MS does not impair left ventricular (LV) systolic function [3], but in some publications it has been shown that MS impairs LV systolic function [4-6]. In the assessment of LV systolic function, a number of imaging techniques - such as echocardiography, MRI, scintigraphy and CT - have been used [7-9]. In the echocardiographical assessment of LV function, the ejection fraction (EF), tissue Doppler imaging (TDI), Doppler strain, and 2D strain have been widely used [10-12]. EF is the most widely used index of contractile function, but due to the visual component, assessment of endocardial excursion is subjective and has high interobserver variability [13]. TDI and Doppler strain are

\section{KARGER \\ Fax +4161306 1234 E-Mail karger@karger.ch} www.karger.com

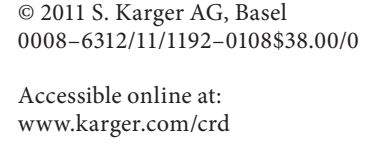


characterized with the limitations of angle dependence, limited spatial resolution, and deformation analysis in one dimension [10]. 2D strain is a novel technique which evaluates LV systolic functions more objectively and quantitatively, and does not have the limitations seen in EF, TDI, and Doppler strain; thus, it has become more commonly used in recent years $[11,12]$. In the diagnosis of LV dysfunction due to MS, some studies have shown EF, TDI, and Doppler strain to be useful [14-17]. However, studies related to the use of $2 \mathrm{D}$ strain, a more objective technique in the diagnosis of LV systolic function in MS, are very limited [18]. In this study, we aimed to evaluate the role of $2 \mathrm{D}$ strain in the assessment of subclinical LV systolic dysfunction and the relationship between stenosis severity and LV dysfunction in patients with MS.

\section{Methods}

\section{Study Population}

In our study, 72 patients with isolated MS and 31 healthy control subjects (group 1) constituted the study population. The 72 patients with MS were classified as those with mild MS (36 patients, group 2), moderate MS (24 patients, group 3), and severe MS (12 patients, group 4). Patients with hypertension, diabetes mellitus, atrial fibrillation, atrioventricular conduction anomalies, moderate to severe valvular heart diseases other than MS, chronic obstructive pulmonary disease, segmental wall motion abnormalities, impaired LV systolic function (EF $\leq 50 \%$ ), and history of coronary artery disease were excluded from the study. Written informed consent was obtained from the patients, and the study was approved by the institutional review board.

\section{Echocardiographic Measurements}

All patients underwent an echocardiographic examination using the GE Vivid 7 system (GE Vingmed Ultrasound AS, Horten, Norway) with a $3.5-\mathrm{MHz}$ transducer. All data were transferred to a workstation for further offline analysis (EchoPAC PC; GE Vingmed Ultrasound AS). LV-EF was calculated using the Simpson's formula from measurement of end-diastolic and end-systolic volumes on apical 4-chamber views [19]. Left atrium posterior-anterior dimension was measured from the parasternal long axis (LAX) view. Pulmonary artery pressure (PAP) was measured from the apical 4-chamber view and was derived from the tricuspid regurgitant jet velocity using the simplified Bernoulli equation assuming a right atrial pressure of $10 \mathrm{~mm} \mathrm{Hg}$. Conventional stenotic indices, such as planimetric mitral valve area (MVA-pln), were calculated by pressure half time (MVA-pht); maximum and mean mitral valve pressure gradient (maximum and mean MVPG) were measured as previously described [20]. MS severity is based on a variety of hemodynamic data, using mean MVPG, systolic PAP, and valve area as follows: mild (area $>1.5 \mathrm{~cm}^{2}$, mean MVPG $<5 \mathrm{~mm} \mathrm{Hg}$, or systolic PAP $<30 \mathrm{~mm} \mathrm{Hg}$ ), moderate (area $1.0-1.5 \mathrm{~cm}^{2}$, mean MVPG 5-10 mm Hg, or systolic PAP 30-50 $\mathrm{mm} \mathrm{Hg}$ ), and severe (area $<1.0 \mathrm{~cm}^{2}$, mean MVPG $>10 \mathrm{~mm} \mathrm{Hg}$, or systolic PAP >50 mm Hg). Mitral valve Wilkins score was mea- sured as described by Wilkins et al. [21]. All images were evaluated by two experienced cardiologists (M.K., I.H.T.) who were blinded to the patients' clinical characteristics.

\section{Two-Dimensional Echocardiography}

$2 \mathrm{D}$ echocardiography images were obtained from LV apical 4-chamber (4C), LAX (long axis) and 2-chamber (2C) views. All images were obtained during breath hold, and stored in cine-loop format from three consecutive beats. The frame rate for images was between 50 and 90 frames/s. All data were transferred to a workstation for further offline analysis. After defining the endocardial border manually, an epicardial tracing was automatically developed by the software system for each view. If the automatically obtained tracking segments were adequate for analysis, the software system was allowed to read the data, whereas analytically inadequate tracking segments were either corrected manually or excluded from the analysis. Strain measurements were reported as the peak longitudinal strain (LS) for $4 \mathrm{C}, \mathrm{LAX}$, and $2 \mathrm{C}$ views, and global strain (GS) was calculated by averaging the three apical views (fig. 1$)$. Strain rate $(\mathrm{Sr})$ measurements were reported as the peak $\mathrm{Sr}$ for $4 \mathrm{C}$, LAX, 2C views and global strain rate (GSr) was calculated by averaging the three apical views (fig. 2).

Statistical Analysis

Continuous variables are expressed as means \pm SD. The level of significance was 0.05 . The Kolmogorov-Smirnov test was used for the normality test of all variables. To compare parametric continuous variables, Independent Student's t test or one-way ANOVA were used; for non-parametric variables the Mann-Whitney U or Kruskal-Wallis tests were used. For categorical variables, the $\chi^{2}$ test was used. Correlations between variables were tested by Pearson or Spearman correlation tests where appropriate. For inter-observer variability for 2D strain parameters, Bland-Altman analysis was used. Statistical analyses were performed using SPSS (SPSS Inc., Chicago, Ill., USA) version 15.0 for Windows.

\section{Results}

The study population consisted of 103 patients (age $40.9 \pm 8.3$ years, $75.7 \%$ female). There were no significant differences between MS patients and control subjects regarding age and gender. The other clinical and echocardiographic characteristics are shown in table 1. There were no significant differences in LV-EF and LV systolic/diastolic dimensions between the groups. Systolic PAP increased significantly from group 1 through to group 4. The median New York Heart Association (NYHA) class of group 3 and 4 was significantly higher than that of group 1 and 2 .

In the analysis carried out between control subjects and MS groups, LV-GS, 4C-LS, LAX-LS, and 2C-LS values were found to be significantly lower in the patients' group. In addition, all Sr values other than LV-LAX-Sr were found to be significantly lower in patients with MS than control subjects (table 2; fig. 3a). 


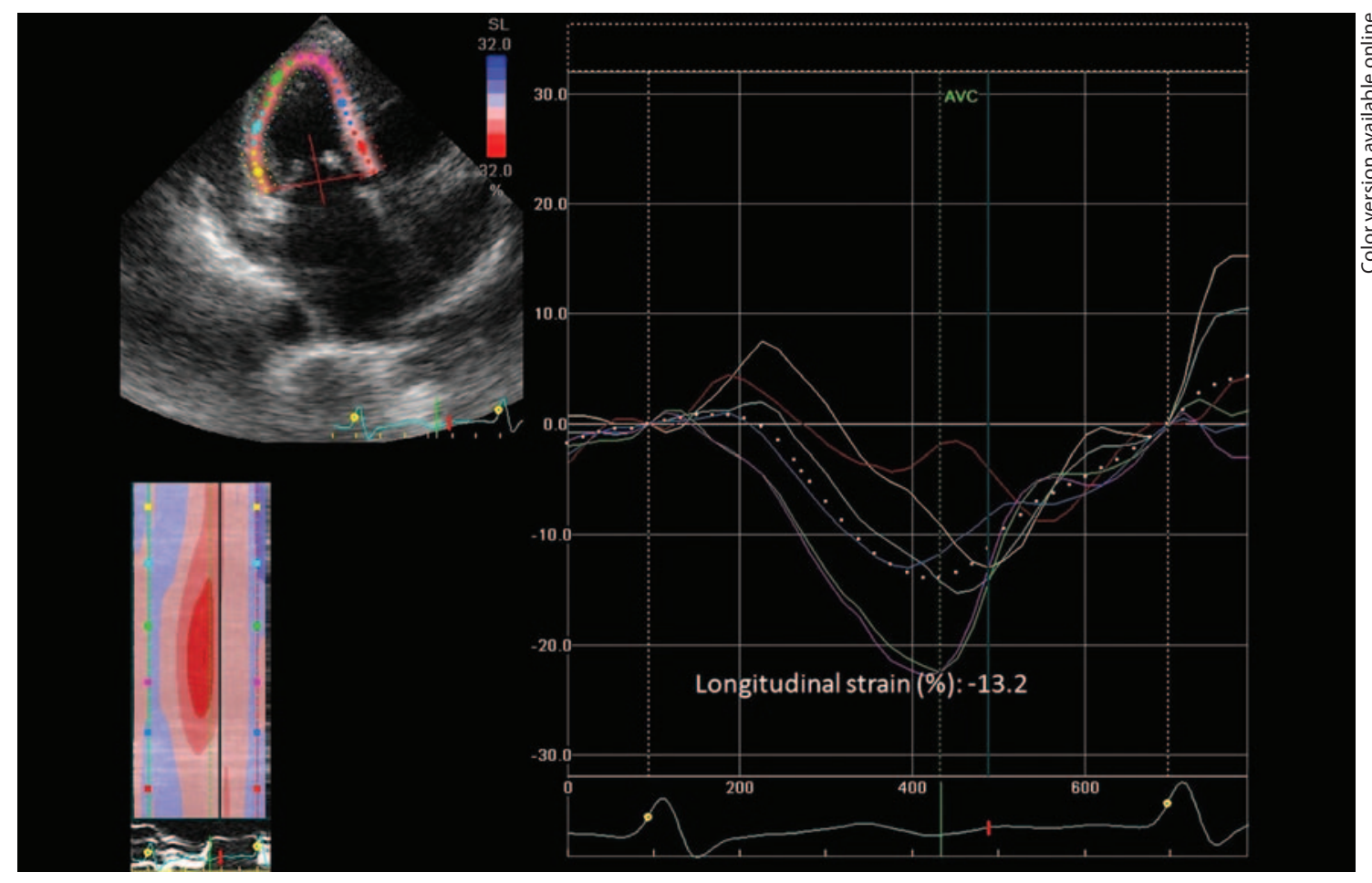

Fig. 1. Apical 4C-LS measurement.

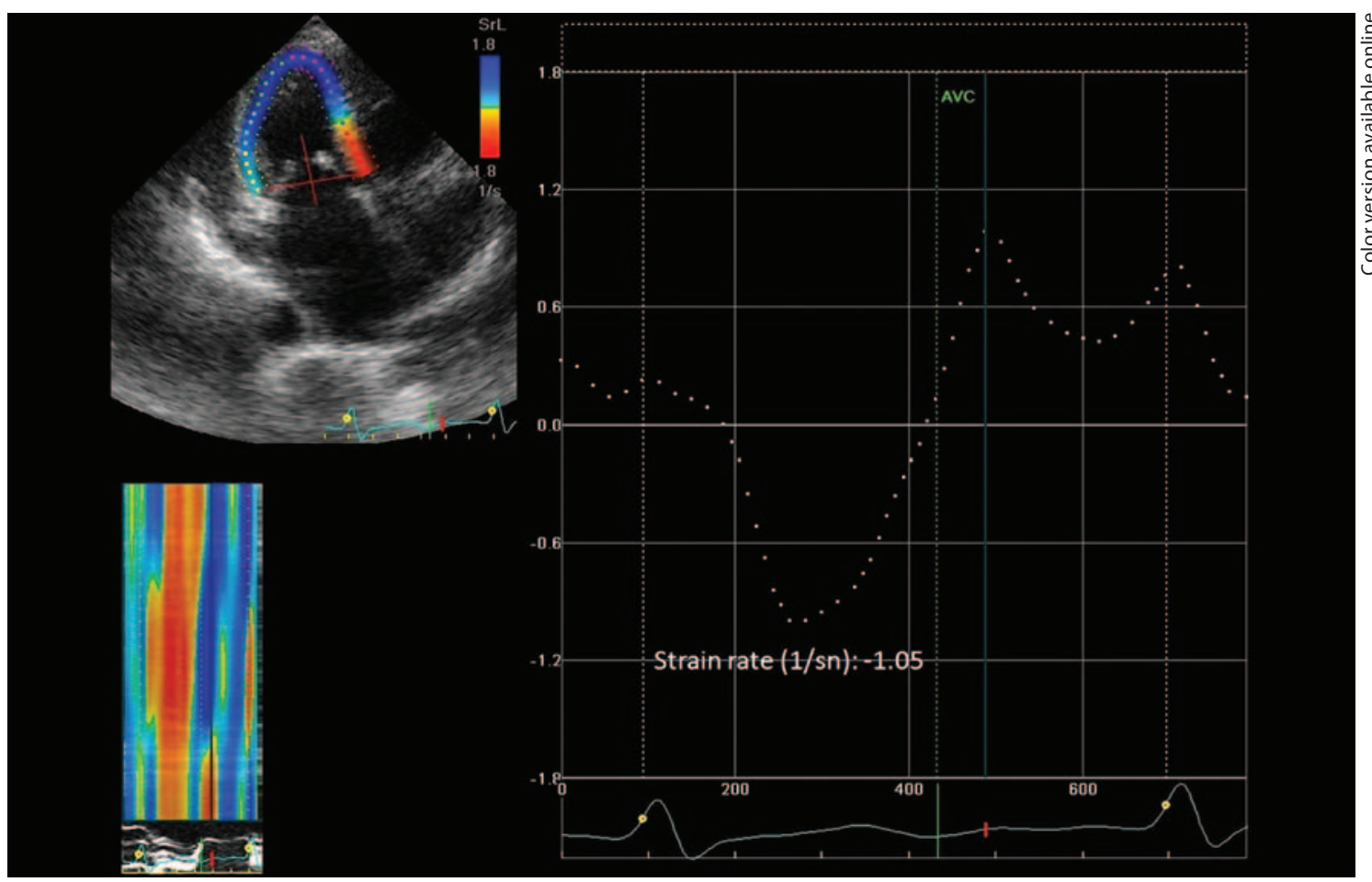

Fig. 2. Apical 4C-Sr measurement. 
Table 1. Clinical and echocardiographic features according to severity

\begin{tabular}{|c|c|c|c|c|c|}
\hline & $\begin{array}{l}\text { Group 1 } \\
(\mathrm{n}=31)\end{array}$ & $\begin{array}{l}\text { Group } 2 \\
(\mathrm{n}=36)\end{array}$ & $\begin{array}{l}\text { Group } 3 \\
(\mathrm{n}=24)\end{array}$ & $\begin{array}{l}\text { Group } 4 \\
(\mathrm{n}=12)\end{array}$ & $\mathrm{p}$ value \\
\hline Age, years & $39.2 \pm 7.8$ & $43.3 \pm 9.8$ & $40.3 \pm 7.1$ & $39.6 \pm 6.1$ & n.s. \\
\hline Female/male & $26 / 5$ & $27 / 9$ & $16 / 8$ & $9 / 3$ & n.s. \\
\hline Ejection fraction, \% & $64 \pm 2.5$ & $64.7 \pm 2.3$ & $63.8 \pm 2.52$ & $62.8 \pm 2.0$ & n.s. \\
\hline PAPs, mm Hg & $20 \pm 3.8$ & $34.7 \pm 5.4$ & $42.1 \pm 6.4$ & $49.1 \pm 5.9$ & $<0.01^{\mathrm{a}}$ \\
\hline MVA-pln, $\mathrm{cm}^{2}$ & - & $2.1 \pm 0.29$ & $1.3 \pm 0.17$ & $0.86 \pm 0.08$ & $<0.001^{\mathrm{a}}$ \\
\hline Maximum gradient, $\mathrm{mm} \mathrm{Hg}$ & - & $10.4 \pm 3.9$ & $17.3 \pm 5.5$ & $25.5 \pm 4.0$ & $<0.001^{\mathrm{a}}$ \\
\hline Mean gradient, $\mathrm{mm} \mathrm{Hg}$ & - & $4.8 \pm 2.2$ & $9.0 \pm 3.4$ & $14 \pm 2.0$ & $<0.001^{\mathrm{a}}$ \\
\hline Left atrial diameter, $\mathrm{cm}$ & $2.7 \pm 0.3$ & $4.1 \pm 0.4$ & $4.6 \pm 0.72$ & $4.6 \pm 0.37$ & $<0.05^{\mathrm{a}}$ \\
\hline NYHA (median) & 1 & 1 & 2 & 2 & $<0.05$ \\
\hline Echo score & - & $5.9 \pm 1.1$ & $7.7 \pm 1.6$ & $8.1 \pm 0.57$ & $<0.001^{\mathrm{b}, \mathrm{c}}$ \\
\hline LV end-diastolic diameter, $\mathrm{cm}$ & $4.58 \pm 0.35$ & $4.56 \pm 0.35$ & $4.79 \pm 0.36$ & $4.6 \pm 0.49$ & n.s. \\
\hline LV end-systolic diameter, $\mathrm{cm}$ & $2.65 \pm 0.33$ & $2.69 \pm 0.31$ & $2.75 \pm 0.40$ & $2.55 \pm 0.55$ & n.s. \\
\hline$\beta$-Blockade (no) & - & 1 & 2 & 2 & n.s. \\
\hline Diuretic (no) & - & - & 2 & 3 & n.s. \\
\hline
\end{tabular}

Where indicated, data presented as means $\pm \mathrm{SD}$.

a All between-group differences statistically significant. ${ }^{b}$ Group 2 vs. 3 statistically significant. ${ }^{c}$ Group 2 vs. 4 statistically significant.

Table 2. LV-2D strain and Sr measurements of control subjects and patients with MS

\begin{tabular}{lllc}
\hline & $\begin{array}{l}\text { Control } \\
(\mathrm{n}=31)\end{array}$ & $\begin{array}{l}\text { MS } \\
(\mathrm{n}=72)\end{array}$ & p value \\
\hline 4C-LS, \% & $19.6 \pm 2.5$ & $17.0 \pm 1.8$ & $<0.001$ \\
LAX-LS, \% & $19.4 \pm 2.2$ & $16.8 \pm 1.6$ & $<0.001$ \\
2C-LS, \% & $19.7 \pm 2.2$ & $16.6 \pm 1.6$ & $<0.001$ \\
4C-Sr, s & $1.62 \pm 0.34$ & $1.28 \pm 0.38$ & $<0.001$ \\
LAX-Sr, s & $1.41 \pm 0.26$ & $1.27 \pm 0.39$ & 0.07 \\
2C-Sr, s & $1.56 \pm 0.37$ & $1.34 \pm 0.41$ & 0.01 \\
GS, \% & $19.6 \pm 2.0$ & $16.8 \pm 1.54$ & $<0.001$ \\
GSr, s & $1.53 \pm 0.21$ & $1.30 \pm 2.8$ & $<0.001$ \\
\hline
\end{tabular}

Table 3. LV-2D strain and Sr measurements of control subjects and subgroups of MS patients

\begin{tabular}{|c|c|c|c|c|c|}
\hline & $\begin{array}{l}\text { Group } 1 \\
(\mathrm{n}=31)\end{array}$ & $\begin{array}{l}\text { Group } 2 \\
(\mathrm{n}=36)\end{array}$ & $\begin{array}{l}\text { Group } 3 \\
(\mathrm{n}=24)\end{array}$ & $\begin{array}{l}\text { Group } 4 \\
(\mathrm{n}=12)\end{array}$ & $\mathrm{p}$ value \\
\hline 4C-LS, \% & $19.6 \pm 2.5$ & $17.5 \pm 1.91$ & $16.9 \pm 1.56$ & $15.9 \pm 1.37$ & $<0.001^{\mathrm{a}, \mathrm{b}, \mathrm{f}}$ \\
\hline LAX-LS, \% & $19.4 \pm 2.2$ & $17.5 \pm 1.48$ & $16.3 \pm 1.56$ & $15.9 \pm 1.34$ & $<0.001^{\mathrm{a}, \mathrm{b}, \mathrm{f}}, 0.03^{\mathrm{c}}, 0.02^{\mathrm{e}}$ \\
\hline 2C-LS, \% & $19.7 \pm 2.2$ & $17.2 \pm 1.92$ & $16.1 \pm 1.1$ & $16.2 \pm 1.18$ & $<0.001^{\mathrm{a}, \mathrm{b}, \mathrm{f}}$ \\
\hline $4 \mathrm{C}-\mathrm{Sr}, \mathrm{s}^{-1}$ & $1.62 \pm 0.34$ & $1.34 \pm 0.29$ & $1.32 \pm 0.48$ & $1.02 \pm 0.35$ & $0.01^{\mathrm{a}, \mathrm{b}},<0.001^{\mathrm{f}}, 0.04^{\mathrm{e}}$ \\
\hline LAX-Sr, $\mathrm{s}^{-1}$ & $1.41 \pm 0.26$ & $1.33 \pm 0.41$ & $1.21 \pm 0.26$ & $1.22 \pm 0.54$ & 0.158 \\
\hline $2 \mathrm{C}-\mathrm{Sr}, \mathrm{s}^{-1}$ & $1.56 \pm 0.37$ & $1.34 \pm 0.46$ & $1.32 \pm 0.32$ & $1.38 \pm 0.44$ & 0.09 \\
\hline GS, \% & $19.6 \pm 2.0$ & $17.4 \pm 1.66$ & $16.4 \pm 1.19$ & $16.0 \pm 1.18$ & $<0.001^{\mathrm{a}, \mathrm{b}, \mathrm{f}}$ \\
\hline $\mathrm{GSr}, \mathrm{s}^{-1}$ & $1.53 \pm 0.21$ & $1.34 \pm 0.25$ & $1.28 \pm 0.25$ & $1.21 \pm 0.37$ & $0.01^{\mathrm{a}}, 0.002^{\mathrm{f}}, 0.004^{\mathrm{b}}$ \\
\hline
\end{tabular}

${ }^{\text {a }}$ Group 1 vs. 2 ; $^{\mathrm{b}}$ group 1 vs. 3 ; $^{\mathrm{c}}$ group 2 vs. $3{ }^{\mathrm{d}}$ group 3 vs. $4{ }^{\mathrm{e}}{ }^{\mathrm{e}}$ group 2 vs. $4{ }^{\mathrm{f}}{ }^{\mathrm{f}}$ group 1 vs. 4. 

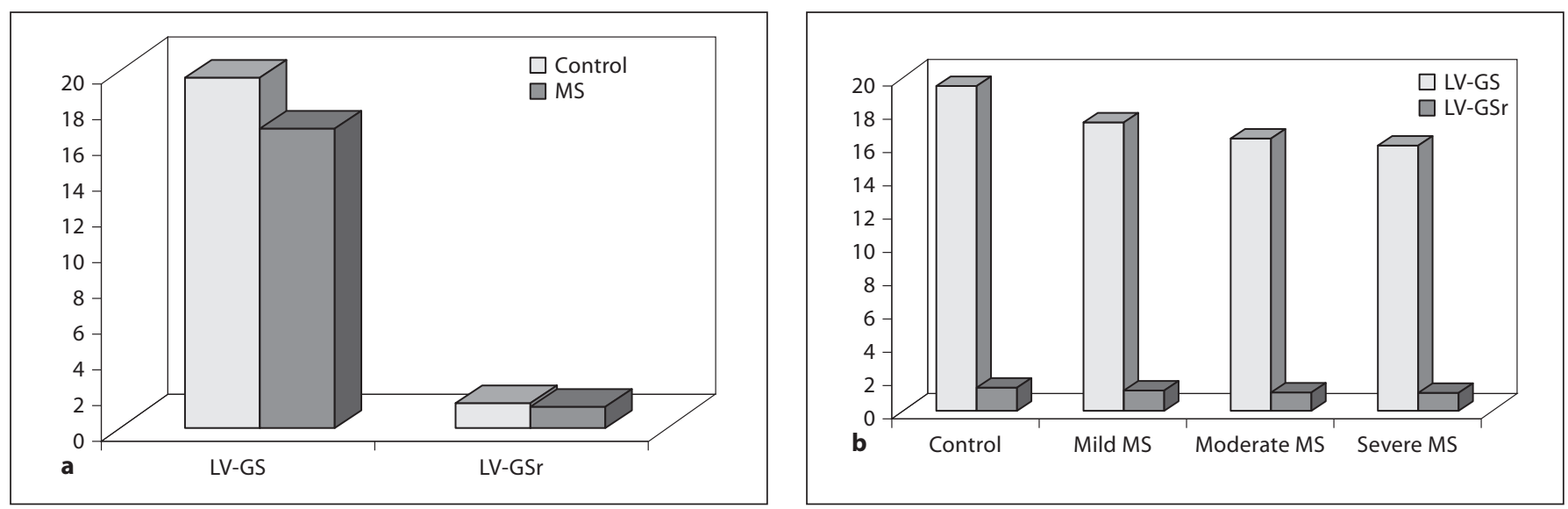

Fig. 3. Comparison of LV-GS and LV-GSr values between patients with MS vs. control subjects (a) and between subgroups of MS patients vs. control subjects (b).

Table 4. Correlations between GS and GSr values and echocardiographic parameters

\begin{tabular}{|c|c|c|c|c|}
\hline & \multicolumn{2}{|l|}{ GS } & \multicolumn{2}{|l|}{ GSr } \\
\hline & $\mathrm{r}$ & $\mathrm{p}$ & $\mathrm{r}$ & $\mathrm{p}$ \\
\hline MVA-pln & 0.30 & 0.008 & 0.22 & 0.05 \\
\hline PAPs & -0.32 & 0.005 & 0.01 & 0.40 \\
\hline Left atrial diameter & -0.10 & 0.37 & -0.10 & 0.37 \\
\hline Mean gradient & -0.26 & 0.03 & 0.01 & 0.98 \\
\hline Maximum gradient & -0.24 & 0.04 & 0.05 & 0.65 \\
\hline Echo score & -0.04 & 0.69 & 0.11 & 0.33 \\
\hline Ejection fraction & 0.40 & 0.001 & 0.40 & 0.001 \\
\hline
\end{tabular}

In the analysis carried out with respect to the severity of MS and considering the values of LV-GS, 4C-LS, LAXLS, and 2C-LS, it was observed that while group 1 had significantly higher values than the other groups, there were not any significant differences between group 2, group 3, and group 4 except for LV-LAX-LS values of group 2, and these values were significantly higher than those of group 3 and group 4 (table 3; fig. 3b).

In the analysis carried out according to the severity of MS for the values LV-GSr, 4C-Sr, LAX-Sr, and 2C-Sr, it was noted that while group 1 had significantly higher values than the other groups, there were not any significant differences between group 2, group 3, and group 4 (table 3; fig. 3b).

In the correlation analysis, there was a moderate correlation between LV-GS with MS indexes (MVA-pln, mean and maximum gradients). No correlation was found between LV-GSr with either left atrial diameter or echo scores. While there was a moderate correlation between LV-GSr with MVA-pln and EF, there was no correlation between the other parameters. (table 4; fig. 4 and 5).

Bland-Altman analysis showed that inter-observer agreement was high.

\section{Discussion}

Our study results indicate that patients with MS had significantly lower measurements of both LV strain and Sr when compared with healthy subjects. Furthermore, both LV strain and Sr measurements did not change as the severity of MS increased. LV-GS values were more closely correlated with both PAPs and conventional mitral stenotic indices than LV-GSr values.

In recent years, $2 \mathrm{D}$ strain imaging has increasingly been used in the assessment of global ventricular function. Being angle-independent, reproducible, and able to provide quantitative data further increases the utility of $2 \mathrm{D}$ strain imaging in evaluation of ventricular functions in clinical settings $[11,12,22]$. In a number of studies, the superiority of 2D strain over TDI and Doppler strain in the assessment of LV regional and global functions has been shown. Examples include ischemic/non-ischemic cardiomyopathy [23] and hypertrophic cardiomyopathy [24]. However, there is only one 2D strain imaging study in the literature related to MS [18].

The existence of LV dysfunction in a quarter of patients with MS has been shown in many studies $[4-6,25]$. Many hemodynamic and myocardial factors have been 

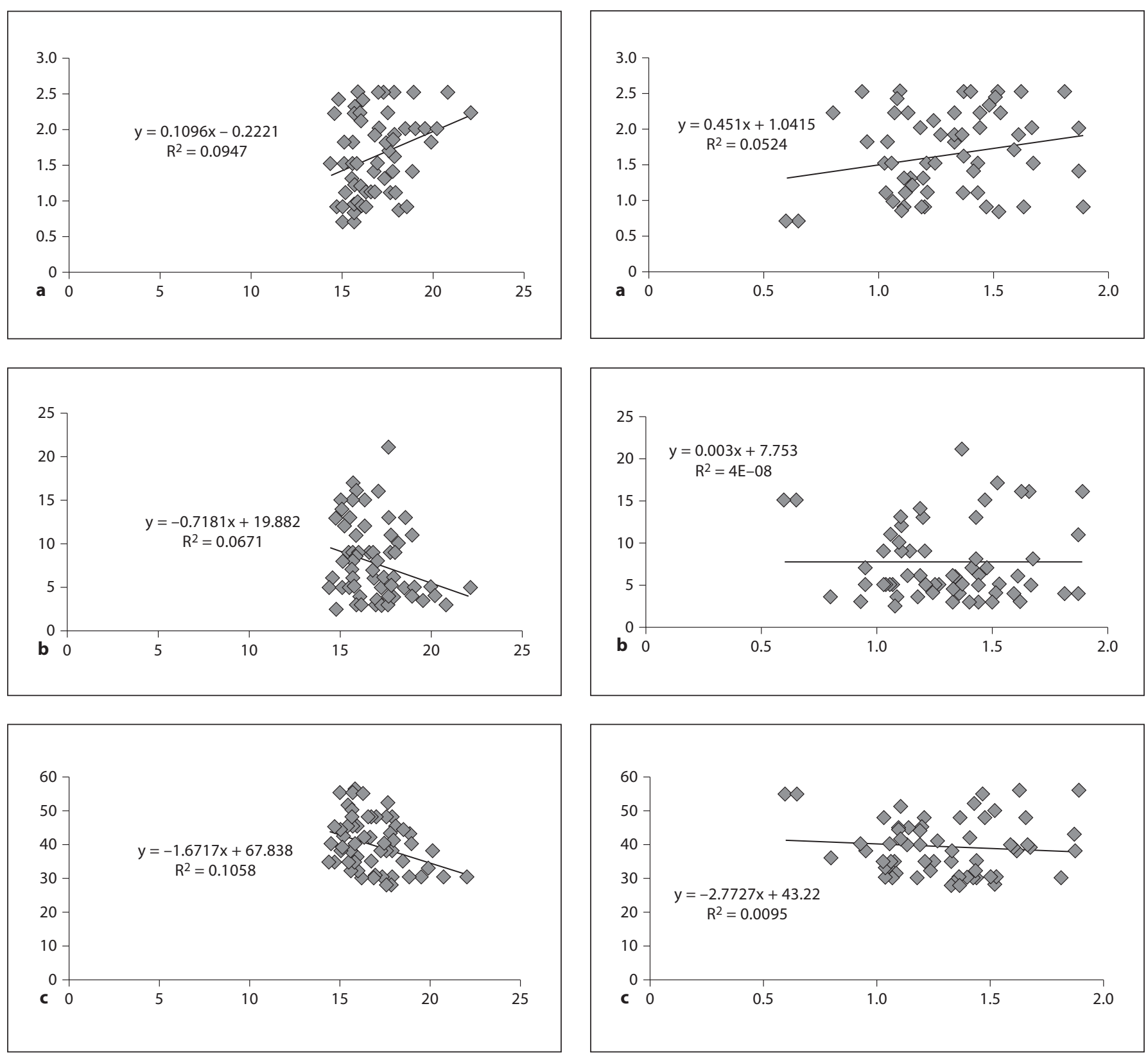

Fig. 4. Correlation between LV-GS and conventional stenotic indices (MVA-pln, a; mean gradient, b) and PAPs (c).

Fig. 5. Correlation between LV-GSr and conventional stenotic indices (MVA-pln, a; mean gradient, b) and PAPs (c).

put forward regarding the LV dysfunction in MS, including reduction in LV filling, chronic myocardial inflammation, scarring of subvalvular apparatus, reduction of LV compliance and diastolic dysfunction, increased afterload, abnormal right-left septal interaction, and pulmonary hypertension [26, 27]. A study by Sengupta et al. [27] showed that mitral annular velocities measured by TDI immediately improved after percutaneous mitral

balloon valvuloplasty, but not EF, and this improvement correlated with the changes in MVA. This finding leads to the consideration that systolic dysfunction in MS depends on myocardial factors rather than hemodynamic factors. Similarly, a unique electron microscopy study in pure MS patients by Lee et al. [28] showed that regardless of LV function, varying degrees of ultrastructural pathologic changes occurred in myocardial muscle cells in all 
examined specimens (myocardial factor), but these impairments did not correlate with the severity of MS. In addition, those patients with abnormal LV function always exhibited more extensive loss of myofibrils. Both of these studies have shown that LV systolic dysfunction in MS is dependent on myocardial factors rather than hemodynamic factors. In our study, we similarly found that patients with MS had lower GS and GSr values when compared with healthy subjects, but there were no significant differences between mild-moderate and advanced groups when considering the severity of MS. These results suggest that subclinical LV dysfunction in patients with MS depends on myocardial factors rather than hemodynamic factors.

Subclinical LV dysfunction related to MS has been evaluated via several different methods. Gash et al. [5] detected that ejection phase indices decreased in patients with LV dysfunction when compared with those who do not have LV dysfunction. Kurtulus et al. [14] used TDI (for the first time), Dogan et al. [17] and Simsek et al. [16] used Doppler strain, and Ozdemir et al. [18] used 2D strain imaging (for the first time) in the assessment of subclinical LV dysfunction in patients with MS. In almost all of these studies, mild and moderate MS patients were included in the studies, while the number of severe MS patients was either very small or excluded. To the best of our knowledge, this study is the first in the literature that includes severe MS patients and has carried out a subgroup analysis. In the analysis, it was observed that subclinical LV dysfunction evaluated by GS and GSr was not related to the severity of MS. In the correlation analysis, we found out that there was a moderate correlation between GS and conventional stenotic indices and correlation was moderate only between GSr and MVA. The fact that the number of patients with severe MS was relatively low $(n=12)$ may affect the generalization of the results of this study in a negative way.

\section{Limitations}

The most important limitation of our present study is the relatively small sample size, particularly in the severe MS group, so the results of this group may not be generalized. However, this study is the only one that includes such a high number of patients with severe MS in the literature. In addition, Doppler strain and segmentary 2D strain analysis were not carried out, and short axis images were not recorded.

\section{Conclusion}

In conclusion, when compared with healthy subjects, patients with MS had lower LV functions using 2D strain and $\mathrm{Sr}$ analysis, and this was independent of the hemodynamic severity of the obstruction. The most probable reason for this finding is rheumatic myocardial involvement or so-called myocardial factor. In the detection of subclinical LV dysfunction in patients with MS, 2D strain imaging appears to be useful.

\section{References}

1 Libby P, Braunwald E: Braunwald's heart disease: A Textbook of Cardiovascular Medicine. Philadelphia, Saunders/Elsevier, 2008.

2 Chandrashekhar Y, Westaby S, Narula J: Mitral stenosis. Lancet 2009;374:1271-1283.

$\checkmark 3$ Carabello BA: Modern management of mitral stenosis. Circulation 2005;112:432-437.

44 Mohan JC, Khalilullah M, Arora R: Left ventricular intrinsic contractility in pure rheumatic mitral stenosis. Am J Cardiol 1989;64: 240-242.

5 Gash AK, Carabello BA, Cepin D, et al: Left ventricular ejection performance and systolic muscle function in patients with mitral stenosis. Circulation 1983;67:148-154.

6 Liu CP, Ting CT, Yang TM, et al: Reduced left ventricular compliance in human mitral stenosis: role of reversible internal constraint. Circulation 1992;85:1447-1456.
7 Shiraki K, Satoh H, Saitoh T, et al: Comparison of global and regional abnormalities in ${ }^{99} \mathrm{~m}$ Tc-sestamibi and cardiac magnetic resonance imaging in dilated cardiomyopathy. J Card Fail 2010;16:641-648.

$\checkmark 8$ Chuang ML, Hibberd MG, Salton CJ, et al: Importance of imaging method over imaging modality in noninvasive determination of left ventricular volumes and ejection fraction: assessment by two- and three-dimensional echocardiography and magnetic resonance imaging. J Am Coll Cardiol 2000;35: 477-484.

$>$ Hundt W, Siebert K, Wintersperger BJ, et al: Assessment of global left ventricular function: comparison of cardiac multidetectorrow computed tomography with angiocardiography. J Comput Assist Tomogr 2005;29: 373-381.
10 Marwick TH: Measurement of strain and strain rate by echocardiography: ready for prime time? J Am Coll Cardiol 2006;47: 1313-1327.

11 Thomas G: Response to 'non-Doppler twodimensional strain imaging by echocardiography - from technical considerations to clinical applications'. J Am Soc Echocardiogr 2007;20:1020.

12 Dandel M, Hetzer R: Echocardiographic strain and strain rate imaging - clinical applications. Int J Cardiol 2009;132:11-24.

13 Kuecherer HF, Kee LL, Modin G, et al: Echocardiography in serial evaluation of left ventricular systolic and diastolic function: Importance of image acquisition, quantitation, and physiologic variability in clinical and investigational applications. J Am Soc Echocardiogr 1991;4:203-214 
14 Ozdemir K, Altunkeser BB, Gok H, et al: Analysis of the myocardial velocities in patients with mitral stenosis. J Am Soc Echocardiogr 2002;15:1472-1478.

-15 Ozer N, Can I, Atalar E, et al: Left ventricular long-axis function is reduced in patients with rheumatic mitral stenosis. Echocardiography 2004;21:107-112.

-16 Simsek Z, Karakelleoglu S, Gundogdu F, et al: Evaluation of left ventricular function with strain/strain rate imaging in patients with rheumatic mitral stenosis. Anadolu Kardiyol Derg 2010;10:328-333.

17 Dogan S, Aydin M, Gursurer M, et al: Predic tion of subclinical left ventricular dysfunction with strain rate imaging in patients with mild to moderate rheumatic mitral stenosis. J Am Soc Echocardiogr 2006;19:243-248.

- 18 Ozdemir AO, Kaya CT, Ozcan OU, et al: Prediction of subclinical left ventricular dysfunction with longitudinal two-dimensional strain and strain rate imaging in patients with mitral stenosis. Int J Cardiovasc Imaging 2010;26:397-404.
9 Schiller NB, Shah PM, Crawford M, et al: Recommendations for quantitation of the left ventricle by two-dimensional echocardiography. American society of echocardiography committee on standards, subcommittee on quantitation of two-dimensional echocardiograms. J Am Soc Echocardiogr 1989;2:358-367.

20 Baumgartner $\mathrm{H}$, Hung J, Bermejo J, et al: Echocardiographic assessment of valve stenosis: EAE/ASE recommendations for clinical practice. Eur J Echocardiogr 2009;10:125.

21 Wilkins GT, Weyman AE, Abascal VM, et al: Percutaneous balloon dilatation of the mitral valve: an analysis of echocardiographic variables related to outcome and the mechanism of dilatation. Br Heart J 1988;60:299308.

22 Teske AJ, De Boeck BW, Melman PG, et al: Echocardiographic quantification of myocardial function using tissue deformation imaging, a guide to image acquisition and analysis using tissue Doppler and speckle tracking. Cardiovasc Ultrasound 2007;5:27.

-23 Donal E, Tournoux F, Leclercq C, et al: Assessment of longitudinal and radial ventricular dyssynchrony in ischemic and nonischemic chronic systolic heart failure: a two-dimensional echocardiographic speckle-tracking strain study. J Am Soc Echocardiogr 2008;21:58-65.
24 Popovic ZB, Kwon DH, Mishra M, et al: Association between regional ventricular function and myocardial fibrosis in hypertrophic cardiomyopathy assessed by speckle tracking echocardiography and delayed hyperenhancement magnetic resonance imaging. J Am Soc Echocardiogr 2008;21:1299-1305.

25 Heller SJ, Carleton RA: Abnormal left ventricular contraction in patients with mitral stenosis. Circulation 1970;42:1099-1110.

26 Klein AJ, Carroll JD: Left ventricular dysfunction and mitral stenosis. Heart Fail Clin 2006;2:443-452.

27 Sengupta PP, Mohan JC, Mehta V, et al: Effects of percutaneous mitral commissurotomy on longitudinal left ventricular dynamics in mitral stenosis: quantitative assessment by tissue velocity imaging. J Am Soc Echocardiogr 2004;17:824-828.

28 Lee YS, Lee CP: Ultrastructural pathological study of left ventricular myocardium in patients with isolated rheumatic mitral stenosis with normal or abnormal left ventricular function. Jpn Heart J 1990;31:435-448. 